\title{
ANALISIS HASIL PEMBELAJARAN MENGGAMBAR BENTUK SISWA SMP NEGERI 3 SINJAI TENGAH
}

\author{
Arham Majid ${ }^{1}$, Benny subiantoro ${ }^{2}$, Ali Ahmad muhdy ${ }^{3}$ \\ ${ }^{123}$ Universitas Negeri Makassara \\ 1arham290398@gmail.com
}

\begin{abstract}
Abstrak
Penelitian ini bertujuan untuk memperoleh data yang akurat mengenai analisis hasil karya gambar bentuk siswa kelas VII SMP Negeri 3 Sinjai Tengah, serta bagaimana teknik penilaian guru terhadap karya gambar bentuk siswa kelas VII SMP Negeri 1 Barru. Jenis penelitian ini adalah evaluatif. Sumber data diperoleh dari guru dan siswa. analisis karya siswa kelas VII SMP Negeri 3 Sinjai Tengah dan teknik penilaian guru terhadap karya siswa, kriteria dalam menganalisis karya gambar siswa yaitu dari aspek proporsi, aspek komposisi, aspek terang gelap, perspektif, kebersihan/kerapihan, dan finishing. karya siswa berjumlah 25 karya yang mandapat kategori sangat baik yaitu berjumlah 1 karya (4\%), yang mendapat kategori baik yaitu berjumlah 2 karya (8\%), yang mendapat kategori sedang yaitu berjumlah 14 karya (56\%). Dan yang mendapat kategori kurang yaitu berjumlah 8 karya (32\%).Teknik penilaian guru mata pelajaran seni budaya dalam menilai karya gambar bentuk siswa menggunakan tiga poin penilaian yaitu dari segi bentuk, kebersihan, dan kerapian karya. Guru mata pelajaran tidak menggunakan banyak aspek-aspek dalam menggambar bentuk ketika menilai karya siswa.
\end{abstract}

Keywords: gambar bentuk, analisis, prinsip-prinsip menggambar bentuk

\section{PENDAHULUAN}

Seni memiliki kekuatan dalam berkomunikasi seperti halnya bahasa, seni juga memiliki kosakata dalam penyampaiannya. Meskipun demikian penyampaiannya bukan dalam kata-kata tetapi berupa elemen-elemen yang dapat dilihat oleh mata, seperti garis, warna, bentuk, ruang, dan lain sebagainya. Menggambar adalah proses menuangkan hasil pikiran atau gabungan semua penginderaan melalui media pensil, pena, spidol, arang pada bidang datar kertas, tembok, atau kanvas.

Menggambar bentuk adalah memindahkan objek/benda-benda yang ada di sekitar kita dengan tepat seperti keadaan benda yang sebenarnya, menurut arah pandang dan cahaya yang ada. Dalam artian, bentuk benda digambarkan secara tepat sesuai dengan keadaannya baik bentuk ataupun warnanya. Gambar bentuk adalah gagasan bentuk yang diwujudkan di atas bidang gambar melalui kemahiran tangan dengan media titik, garis, bidang, bentuk, warna, tekstur, dan gelap terang yang dibuat dengan memperhatikan ketepatan bentuk dan perspektif, proporsi, serta komposisi sehingga menghasilkan karya yang bagus.

Pentingnya pembelajaran seni budaya dalam dunia pendidikan merupakan sarana dan media yang bisa digunakan untuk mengembangkan dan menumbuhkan kreativitas siswa dalam usaha dalam meningkatkan daya kerja yang lebih efektif menuju kemandirian sikap dan karya. Dalam pelaksanaan pembelajaran seni budaya khususnya pembelajaran gambar bentuk banyak faktor yang sangat mempengaruhi proses pembelajaran berupa materi pembelajaran, strategi pembelajaran, metode pembelajaran, media pembelajaran, dan minat belajar siswa.

Pembelajaran gambar bentuk di SMP Negeri 3 Sinjai Tengah mengenai defenisi gambar bentuk, teknik menggambar bentuk, 
serta media dan alat menggambar bentuk dengan bahasa yang mudah dimengerti oleh siswa. Penelitian ini bermaksud untuk mengamati hasil karya gambar bentuk siswa SMP Negeri 3 Sinjai Tengah sekaligus penilaian guru seni budayanya. Berhubung guru mata pelajaran seni budaya ini bukan lulusan dari Jurusan Seni melainkan Jurusan IPS, membuat penelit bertanya-tanya bagaimana teknik penilaian guru seni budaya yang bukan berbasis seni tersebut dalam memberikan penilaian terhadap karya siswa SMP Negeri 3 Sinjai Tengah.

Secara umum kemampuan menggambar setiap siswa sangat berbedabeda. Perbedaan kemampuan pada siswa tersebut merupakan tantangan bagi guru mata pelajaran seni budaya dalam memberikan penilaian. Contohnya dalam menilai karya gambar bentuk guru mata pelajaran harus tahu bagaimana itu gambar bentuk, tau tentang teori gambar bentuk dan lain sebagainya.

Berdasarkan uraian di atas, penulis melakukan penelitian tentang analisis gambar bentuk karya siswa SMP Negeri 3 Sinjai Tengah serta Teknik penilaian guru terhadap karya siswa.

Menurut Kamus Besar Bahasa Indonesia, Edisi ke IV analisis adalah penyelidikan terhadap suatu peristiwa (karangan, perbuatan, dan sebagainya) untuk mengetahui keadaan yang sebenarnya. Analisis adalah penguraian suatu pokok atas berbagai bagiannya dan penelaahan bagian itu sendiri serta hubungan antara bagian untuk memeroleh pengertian yang tepat dan pemahaman arti keseluruhan.

Abd. Haling, dkk (2007: 43), Mengemukakan bahwa analisis meliputi perilaku menjabarkan atau menguraikan (breakdown) konsep menjadi bagian-bagian yang lebih rinci dan menjelaskan keterkaitan atau hubungan antara bagian tersebut.

Dalam Kamus Besar Bahasa Indonesia (1988: 250) dijelaskan bahwa gambar adalah tiruan, barang (manusia, binatang, dsb.) yang dilihat dengan coretan pada kertas. Menggambar atau drawing adalah unsur rupa paling mendasar dalam seni rupa dan merupakan bahasa paling universal yang sudah ada sebelum manusia menemukan bahasa tulisan. Gambar adalah informasi dan ekspresi. Oleh karena itu harus bersifat informatif dan komunikatif (Apriyatno, 2013).

Menggambar bentuk merupakan kegiatan untuk mewujudkan ilusi (bayangan atau angan-angan) melalui gambar. Ilusi itu dapat mengenai benda yang sedang dilihat atau benda yang tidak sedang dilihat tetapi pernah dilihat oleh penggambar. Oleh karena itu ada dua jenis kegiatan menggambar bentuk, yaitu menggambar objek yang sedang dihadapi, yang disebut menggambar alam benda dan menggambar objek berdasarkan ingatan. Gambar bentuk adalah gambar dengan objek gambar yang nyata, serta memiliki volume, efek bahan, bayangan, maupun kelengkapan sebagai bentuk yang utuh (Sachari, 2004: 59).

Menggambar bentuk bertujuan untuk menirukan penampakan sebuah atau sekelompok benda ke atas bidang gambar. Untuk itu, dalam menggambar bentuk mesti ada sebuah atau sekumpulan benda untuk dijadikan sasaran gambar. Tanpa kehadiran sasaran gambar ini, mustahil kegiatan menggambar bentuk dapat terlaksana. Karena yang menjadi tujuan menggambar bentuk adalah menghasilkan gambar yang secara tepat menirukan sasaran gambar. Menggambar bentuk biasa pula disebut dengan nama "menggambar alam-benda (still life)". Penamaan ini berdasarkan pada kenyataan bahwa yang menjadi sasaran gambar adalah alam-benda seperti: botol, sepatu, kotak, tas, buah-buahan, panci, pot, teko, lampu meja, dan sebagainya. Menggambar bentuk dengan menggunakan manusia sebagai sasaran gambar, biasanya disebut "menggambar bentuk anatomi" atau "menggambar model" (Salam, 2001: 46).

Secara umum bentuk benda dibedakan menjadi tiga yaitu:

1) Bentuk kubistis adalah benda-benda yang bentuknya menyerupai kubus (balok). Misalnya meja, kursi, lemari, dan sebagainya. 
2) Bentuk silindris adalah benda-benda yang bentuknya menyerupai silinder (elips). Misalnya botol, gelas, piring, mangkuk, teko, dan sebagainya.

3) Bentuk bebas adalah benda-benda yang bentuknya tidak beraturan. Misalnya buahbuahan, pepohonan, batu-batuan dan benda-benda alam lainya.

Berikut unsur-unsur seni rupa dapat dijabarkan sebagai berikut: Titik merupakan elemen terkecil dalam seni rupa dibandingkan dengan elemen-elemen lainnya. Titik yang berkelompok akan melahirkan bentuk atau bidang, titik yang berderet akan membentuk garis. Teknik melukis dengan menggunakan elemen titik ini terkenal dengan sebutan "pointilisme" (Nurhadiat, 2004: 23).

Garis adalah dua buah titik yang di hubungkan, atau sederetan dari sejumlah titik (Subiantoro, 2014: 32). Bidang adalah area yang memiliki luas karena pertemuan beberapa garis dan memiliki panjang dan lebar. Bidang dapat dibedakan menjadi bidang horizontal, vertikal dan diagonal. Dapat pula dibedakan menjadi bidang geometris dan non geometris. Bidang geometris adalah bidang yang memiliki kesan formal dan sedikit kaku, seperti lingkaran, persegi empat, persegi panjang, elips, segitiga, dan sebagainya. Sedangkan bidang non geometris adalah bidang yang memiliki kesan tidak formal, santai, dinamis, dan bentuknya tidak beraturan.

Warna merupakan pigmen atau serbuk yang dipadatkan menjadi batangan maupun serbuk yang dibuat pasta serta dicairkan. Menurut Wikipedia Warna adalah spektrum tertentu yang terdapat di dalam suatu cahaya sempurna (berwarna putih), identitas suatu warna ditentukan oleh panjang gelombang cahaya tersebut (Rachmat04, 2019). Warna mempunyai sifat-sifat yang berbeda tergantung dengan bahan yang akan digunakan. Warna dapat disusun secara kontras maupun harmonis. Warna kontras yaitu perpaduan warna yang saling berseb rangan, sedangkan warna harmonis yaitu perpaduan warna-warna yang hampir mirip. Warna dibedakan menjadi 3 macam, yakni warna primer, sekunder, dan tersier. Warna primer adalah warna baku dan terbentuk tanpa ada pencampuran warna. Kelompok warna yang termasuk ke dalam warna primer yaitu warna merah, biru dan kuning. Warna sekunder yaitu pencampuran antara dua warna primer, seperti hijau (pencampuran antara warna biru dan kuning), orange (pencampuran antara warna merah dan kuning), ungu (pencampuran antara warna biru dan merah). Warna tersier adalah pencampuran antara warna primer dan warna sekunder, misalnya warna toska yaitu pencampuran antara warna biru dengan warna hijau.

Bentuk merupakan unsur seni rupa yang memiliki volume. Bentuk memiliki tiga dimensi, yaitu panjang, lebar dan tinggi. Bentuk juga dibagi menjadi dua, yaitu bentuk geometris dan bentuk non geometris. Gelap terang adalah tingkatan value yang bisa terjadi antara warna hitam dan putih atau antara warna gelap. Gelap terang sangat penting untuk memberikan penonjolan pada unsur tertentu atau untuk memberikan kesan kontras, kesan ruang, kesan jauh dekat, dan kesan volume.

Tekstur merupakan sifat atau karakter dari permukaan suatu benda. Tekstur dapat berupa halus, bergelombang, kasar, lunak, keras, lembut dan sebagainya. Tekstur dibedakan menjadi tekstur nyata dan tekstur semu. Tekstur nyata adalah tekstur yang apabila diraba permukaanya terasa kasar atau halus di kulit. Sedangkan tekstur semu adalah tekstur yang apabila diraba tidak bisa dirasakan oleh kulit. Tekstur nyata dapat berupa kapas, karung goni, kain sutera, amplas, sabut kelapa, karet busa dan lainnya. Sedangkan tekstur semu dapat berupa hasil cetakan irisan belimbing, tekstur koin di kertas, tekstur anyaman bambu di kertas dan sebagainya.

Berikut aspek-aspek penting di dalam menggambar bentuk yaitu:

1). Ketepatan Bentuk (anatomi)

a). Proporsi, Proporsi adalah unsur kesebandingan ideal yang dapat diserap oleh persepsi pengamat sehingga terjadi keseimbangan harmonis objek gambar (Sachari, 2004: 67). 
b). Perspektif, Perspektif biasa juga disebut ilmu melihat. Dikatakan ilmu melihat karena satu-satunya ilmu yang dapat memberi petunjuk bagaimana membuat gambar pada bidang datar, sehingga kesan yang diperoleh pada waktu melihat gambar sama dengan kesan yang diperoleh pada waktu melihat bendanya (Rapi, 2015: 1)

\section{2). Komposisi Gambar}

a). Keseimbangan yaitu pengaturan bendabenda bergerak atau tidak bergerak, dinamis atau statis, setiap benda ditempatnya harus saling mengimbangi (Sulastianto, 2006: 184).

b). Kesatuan. pada sebuah karya seni rupa, paduan usur-unsur visual dan karakter yang berbeda menjadi kesatuan yang saling mengisi agar tercapainya karya yang sempurnah dan indah (Sulastianto, 2006: 14).

c). Irama. agar sebuah karya seni tidak membosankan, karya tersebut harus memiliki irama, yang dimaksud disini yaitu tebal dan tipis, panjang dan pendek, lurus dan lengkung serta adanya warnah gelap dan terang (Nurhadiat, 2004: 23).

\section{3). Gelap Terang Pada Gambar}

Unsur gelap terang pada karya seni rupa timbul karena adanya perbedaan intensitas cahaya yang jatuh pada permukaan benda. Perbedaan ini menyebabkan munculnya tingkat nada warna (value) yang berbeda. Bagian yang terkena cahaya akan lebih terang dan bagian yang kurang atau terkena cahaya akan tampak lebih gelap.

\section{4). Bayangan Benda atau Bayang-Bayang}

Menurut Wikipedia apabila cahaya terhalang sesuatu benda, maka terbentuklah bayang-bayang. Cahaya merambat dalam garis lurus. Bila cahaya terhalang suatu benda maka akan muncul bayangan dari benda penghalang tersebut. Kekuatan sinar menentukan tebal tipisnya bayangan benda itu, panjang bayangan benda ditentukan oleh sudut ketinggian sumber cahaya, dan besar kecilnya bayangan benda ditentukan dari dekat jauhnya benda dari sumber cahaya (HsfBot, 2018). bentuk:

Berikut beberapa teknik menggambar
Teknik Arsir. Teknik Arsir lebih menekankan pada kekuatan garis (stroke). Dilakukan berulang-ulang secara sejajar maupun tumpang berpotongan, hal ini dilakukan untuk memberikan kesan gelap. Atau dapat dilakukan secara sejajar dengan memperhatikan kerapatannya saja, apabila dilakukan dengan rapat menyebabkan kesan gelap dan sebaliknya. Atau menggunakan tekanan ringan dan kuat dilakukan secara berulang-ulang.

Teknik Dussel. Teknik Dussel atau Teknik Gosok menggambar dengan cara menggosok-gosokkan tangan atau kertas yang sudah diberi atau dibubuhi dengan pensil. Teknik Stipel. Teknik Stipel yaitu menggambar dengan titik atau noda-noda yang diulang-ulang.

Berikut adalah beberapa media dan alat dalam menggambar bentuk yaitu:

Kertas. Kertas adalah bahan (bidang gambar) yang paling ideal digunakan untuk menggambar. Pensil. Istilah "pensil" berasal dari bahasa latin pencilus yang berarti "ekor kecil" yang ditujukan bagi kuas untuk menggambar dengan tinta (Salam, 2001: 73). Kapur, Pastel dan Krayon. kapur atau pastel terbuat dari serbuk warna yang kering yang dicampur dengan bahan perekat sehingga terbentuk semacam pasta atau adonan dengan ban pelarut air (Salam, 2001: 73). Marker atau Spidol. Marker digunakan untuk menciptakan garis-garis atau untuk mengisi bidang (Salam, 2001: 73). Stip Karet (Penghapus)Menurut Wikipedia penghapus merupakan salah satu perlengkapan alat tulis yang merupan karet lembut yang mampu menghilangkan tanda yang dihasilkan oleh pensil (AABot, 2019).

Penilain karya siswa bertujuan untuk mendapatkan informasi mengenai seberapa jauh kemampuan siswa dalam berkarya gambar bentuk.

\section{METODE}

Jenis penelitian ini adalah evaluatif. Sumber data diperoleh dari guru dan siswa. analisis karya siswa kelas VII SMP Negeri 3 Sinjai Tengah dan teknik penilaian guru terhadap karya siswa, kriteria dalam menganalisis karya gambar siswa yaitu dari 


\section{imajinassi}

aspek proporsi, aspek komposisi, aspek terang gelap, perspektif, kebersihan/kerapihan, dan finishing.

\section{HASIL DAN PEMBAHASAN \\ Hasil}

Analisis karya gambar bentuk siswa SMP Negeri 3 Sinjai Tengah

Analisis karya siswa kelas VII SMP Negeri 3 Sinjai Tengah dengan menggunakan aspek ketepatan bentuk, komposisi, gelapterang, kerapihan/kebersihan, dan finising.

a. Gambar Alvin Agus Setiawan

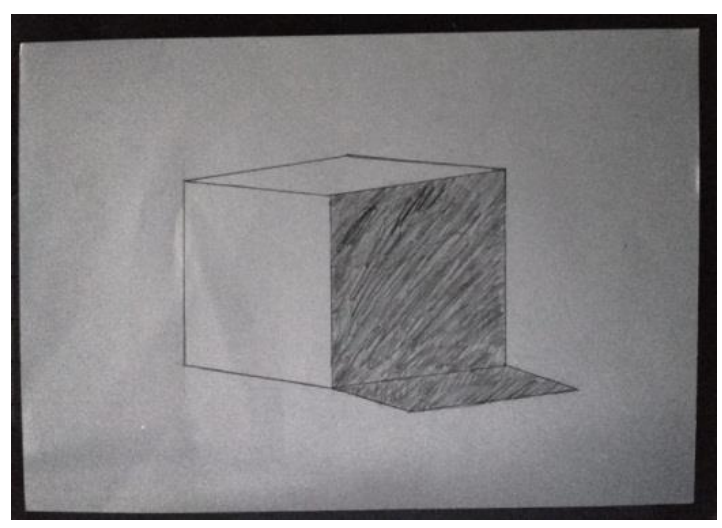

Gambar 1. Alvin Agus Setiawan

$>\quad$ Dilihat dari aspek ketepatan bentuk yang meliputi aspek proporsi dan aspek perspektif. Aspek proporsi yaitu bentuk antara sisi-sisi dari gambar kotak terlihat sebanding, hanya saja bagian sudut kanan atas sedikit tinggi dan perbandingan antara ukuran kertas dengan ukuran gambar terlihat seimbang, tidak terlalu kecil dan tidak terlalu besar. Aspek perspektif yaitu menggunakan perspektif mata normal dimana bagian atas terlihat sedikiti sedangkan bagian bawah benda tidak terlihat sama sekali, hanya saja bagian belakang sebelah kanan sedikit tinggi.

Dilihat dari aspek komposisi yang meliputi keseimbangan, kesatuan, dan irama. Keseimbangan yaitu penempatan objek gambar tepat di tengah bidang gambar terlihat keseimbanagan antara bagian kanan dan kiri serta bagian atas dan bawah. Kesatuan yaitu adanya unsur-unsur seni rupa yang digunakan antara lain titik, garis, dan bidang yang membentuk satu kesatuan sehingga terbentuk gambar kotak. Irama yaitu adanya pengulangan garis pada bagian gambar sehingga terbentuk banyang-bayang yang membedakan bagian yang terkena cahaya dan yang tidak terkena cahaya.

Dilihat dari aspek gelap-terang yaitu menggelapkan bagian yang tidak terkena cahaya terlihat arsiran pensil pada bagian kanan dan pemberian bayangan benda pada gambar.

$>$ Dilihat dari aspek kebersihan dan kerapihan yaitu terlihat bersih dan rapih tanpa ada noda dan coretan lainnya selain gambar kotak yang ada pada kertas gambar.

Dilihat dari aspek finishing yaitu kelengkapan objek gambar yaitu adanya gambar kotak dan juga adanya bayangan kotak.

b. Gambar Asran

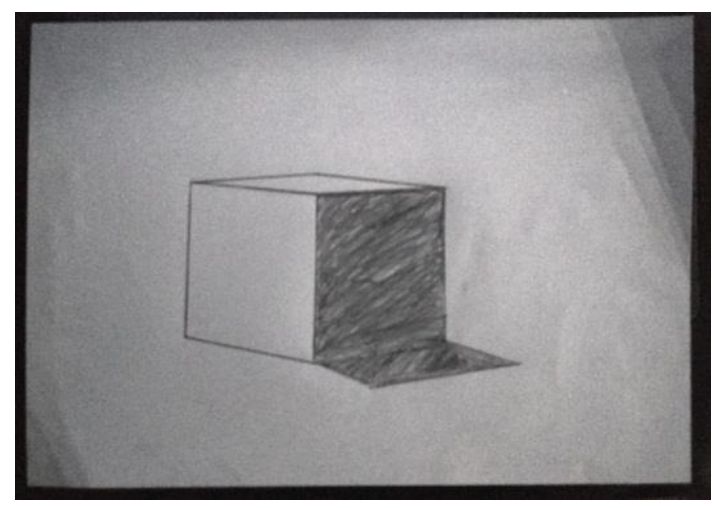

Gambar 2. Asran

Dilihat dari aspek ketepatan bentuk yang meliputi aspek proporsi dan aspek perspektif. Aspek proporsi yaitu bentuk antara sisi-sisi dari gambar kotak terlihat sebanding antara bagian kanan dan kiri. Perbandingan antara ukuran kertas dengan ukuran gambar juga terlihat seimbang, tidak terlalu kecil dan tidak terlalu besar. Aspek perspektif yaitu menggunakan perspektif mata normal di mana bagian atas terlihat sedikit. Sedangkan bagian bawah benda 
tidak terlihat sama sekali. Hanya arah bayangan benda yang sedikit ke bawah.

Dilihat dari aspek komposisi yang meliputi keseimbangan, kesatuan, dan irama. Keseimbangan yaitu penempatan objek gambar sedikit ke kanan dan sedikit ke bawah haya saja dengan adanya bayangan benda jadi terlihat seimbang antara bagian kanan dan kiri kertas gambar. Kesatuan yaitu adanya unsur-unsur seni rupa yang digunakan antara lain titik, garis, dan bidang yang membentuk satu kesatuan sehingga terbentuk gambar kotak. Irama yaitu adanya pengulangan garis pada bagian kanan gambar sehingga terbentuk banyang-bayang yang membedakan bagian yang terkena cahaya dan yang tidak terkena cahaya.

Dilihat dari aspek gelap-terang yaitu menggelapkan bagian yang tidak terkena cahaya terlihat arsiran pensil pada bagian kanan dan pemberian bayangan benda pada gambar.

$>$ Dilihat dari aspek kebersihan dan kerapihan yaitu terlihat bersih tanpa ada noda dan coretan lainnya selain gambar kotak yang ada pada kertas gambar. Hanya saja bagian sudut kertas terlihat lipatan-lipatan sehingga kertas gambar terlihat tidak rapih

> Dilihat dari aspek finishing yaitu kelengkapan objek gambar yaitu adanya gambar kotak dan juga adanya bayangan kotak

c. Gambar Fajri Alim

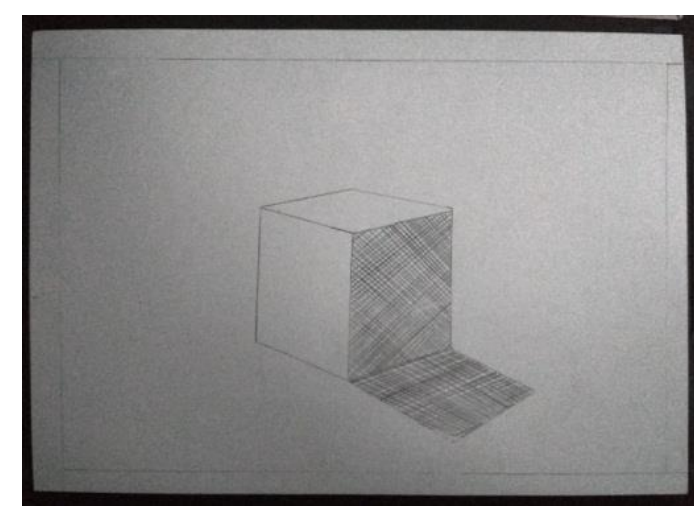

Gambar 3. Fajri Alim
Dilihat dari aspek ketepatan bentuk yang meliputi aspek proporsi dan aspek perspektif. Aspek proporsi yaitu bentuk antara sisi-sisi dari gambar kotak terlihat seimbang atara bagian kanan dan kiri. Penggunaan garis pinggir yang menjadikan antara ukuran kertas gambar dan gambar terlihat seimbang. Aspek perspektif yaitu menggunakan perspektif mata burung yang harusnya menggunakan perspektif mata normal. Arah bayangan benda juga terlihat benar.

Dilihat dari aspek komposisi yang meliputi keseimbangan, kesatuan, dan irama. Keseimbangan yaitu penempatan objek gambar tepat di tengah bidang gambar dimana terlihat keseimbanagan antara bagian kanan dan kiri serta bagian atas dan bawah. Hanya saja bayangan benda yang terlalu panjang menyebabkan ketidak seimbangan bagian atas dan bawah pada kertas gambar. Kesatuan yaitu adanya unsurunsur seni rupa yang digunakan antara lain titik, garis, dan bidang yang membentuk satu kesatuan sehingga terbentuk gambar kotak. Irama yaitu adanya pengulangan garis pada bagian kanan gambar sehingga terbentuk banyang-bayang yang membedakan bagian yang terkena cahaya dan yang tidak terkena cahaya.

Dilihat dari aspek gelap-terang yaitu menggelapkan bagian yang tidak terkena cahaya terlihat arsiran pensil pada bagian kanan dan pemberian bayangan benda pada gambar.

Dilihat dari aspek perspektif yaitu menggunakan perspektif mata burung yang harusnya menggunakan perspektif mata normal. Arah bayangan benda juga terlihat benar.

Dilihat dari aspek kebersihan dan kerapihan yaitu terlihat bersih dan rapih tanpa ada noda dan coretan lainnya selain gambar kotak yang ada pada kertas gambar.

Dilihat dari aspek finishing yaitu kelengkapan objek gambar yaitu adanya gambar kotak dan juga adanya bayangan kotak. 


\section{d. Gambar Asyifa Auliya}

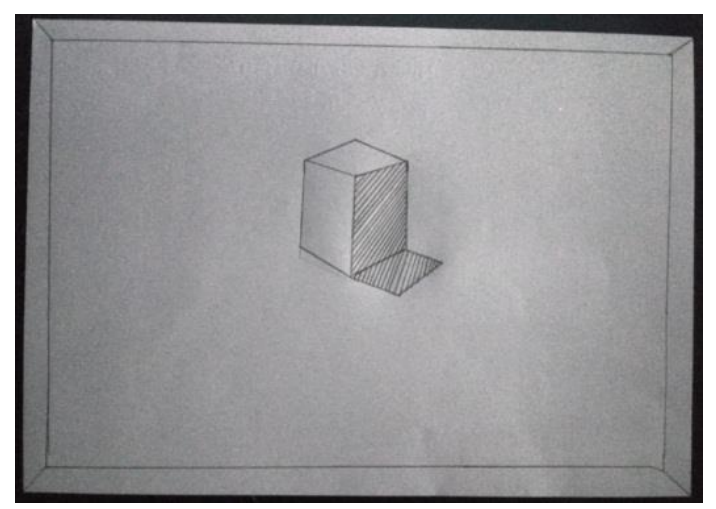

Gambar 4. Asyifa Aulia

Dilihat dari Aspek ketepatan bentuk yang meliputi aspek proporsi dan aspek perspektif. Aspek proporsi yaitu bentuk antara sisi-sisi dari gambar menyerupai balok bukan kotak terlihat bagian atas berbentuk segi empat sedangkan bagian samping berbentuk persegi panjang dan perbandingan antara ukuran kertas dengan ukuran gambar juga terlihat tidak seimbang yang mana ukuran gambar sedikit kecil walaupun sudah menggunakan garis pinggir. Aspek perspektif yaitu menggunakan perspektif mata burung yang harusya menggunakan perspektif mata normal. Kita seakan-akan melihat benda dari atas karena bagian sudut atas belakang terlalu tinggi. Sedangkan arah bayangan benda sudah terlihat benar.

Dilihat dari aspek komposisi yang meliputi keseimbangan, kesatuan, dan irama. Keseimbangan yaitu penempatan objek gambar sedikit ke atas kertas gambar terlihat ketidak seimbangan antara bagian atas dan bagian bawah kertas gambar. Kesatuan yaitu adanya unsur-unsur seni rupa yang digunakan antara lain titik, garis, dan bidang yang membentuk satu kesatuan sehingga terbentuk gambar kotak. Irama yaitu adanya pengulangan garis pada bagian kanan gambar sehingga terbentuk banyang-bayang yang membedakan bagian yang terkena cahaya dan yang tidak terkena cahaya.

Dilihat dari aspek gelap-terang yaitu menggelapkan bagian yang tidak terkena cahaya terlihat arsiran pensil pada bagian kanan dan pemberian bayangan benda pada gambar.

Dilihat dari aspek kebersihan dan kerapihan yaitu terlihat bersih dan rapih tanpa ada noda dan coretan lainnya selain gambar kotak yang ada pada kertas gambar.

Dilihat dari aspek finishing yaitu kelengkapan objek gambar yaitu adanya gambar kotak dan juga adanya bayangan kotak.

\section{e. Gambar Ainul Astriani}

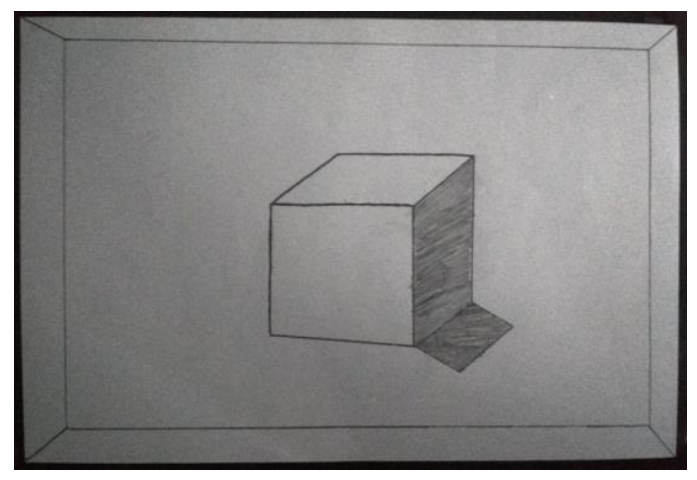

Gambar 5. Ainul Astriani

Dilihat dari aspek ketepatan bentuk yang meliputi aspek proporsi dan perspektif. Aspek proporsi yaitu bentuk antara sisi-sisi dari gambar kotak terlihat seimbang hanya saja bagian belakang kotak sedikit tinggi dan garis pinggir di sini sangat berfungsi menjadikan ukuran objek gambar dan kertas terlihat seimbang. Aspek perspektif yaitu menggabungkan dua perspektif yaitu perspektif mata burung dan mata normal yang harusnya hanya menggunakan perspektif mata normal. Sedangkan arah bayangannya terlalu mengarah ke bawah.

Dilihat dari aspek komposisi yang meliputi keseimbangan, kesatuan, dan irama. Keseimbangan yaitu penempatan objek gambar terlihat sedikit ke kiri dan 
sedikit ke bawah apalagi dengan adanya bayangan benda terlihat sekali ketidak seimbangan tersebut pada kertas gambar. Kesatuan yaitu adanya unsurunsur seni rupa yang digunakan antara lain titik, garis, dan bidang yang membentuk satu kesatuan sehingga terbentuk gambar kotak. Irama yaitu adanya pengulangan garis pada bagian kanan gambar sehingga terbentuk banyang-bayang yang membedakan bagian yang terkena cahaya dan yang tidak terkena cahaya.

Dilihat dari aspek gelap-terang yaitu menggelapkan bagian yang tidak terkena cahaya terlihat arsiran pensil pada bagian kanan dan pemberian bayangan benda pada gambar.

Dilihat dari aspek perspektif yaitu menggabungkan dua perspektif yaitu perspektif mata burung dan mata normal yang harusnya hanya menggunakan perspektif mata normal. Sedangkan arah bayangannya terlalu mengarah ke bawah.

> Dilihat dari aspek kebersihan dan kerapihan yaitu terlihat bersih dan rapih tanpa ada noda dan coretan lainnya selain gambar kotak yang ada pada kertas gambar.

$>$ Dilihat dari aspek finishing yaitu kelengkapan objek gambar yaitu adanya gambar kotak dan juga adanya bayangan kotak

\section{Pembahasan}

Analisis Karya Gambar Bentuk Siswa SMP Negeri 3 Sinjai Tengah

Dari hasil analisis dengan menggunakan aspek-aspek penilaian antara lain dari aspek proporso, aspek komposisi, aspek terang gelap, aspek perspektif, aspek kebersihan / kerapihan, dan finishing. Pedoman yang digunakan untuk mengetahui kesimpulan dari analisis karya tersebut antara lain:
Tabel 4. kriteria dalam menilai kemampuan siswa SMP Negeri 3 Sinjai Tengah

\begin{tabular}{|c|l|r|}
\hline No & $\begin{array}{l}\text { Aspek Dalam } \\
\text { Menganalisis }\end{array}$ & Poin \\
\hline 1 & Proporsi & $1-4$ \\
\hline 2 & Komposisi & $1-4$ \\
\hline 3 & Terang Gelap & $1-4$ \\
\hline 4 & Perspektif & $1-4$ \\
\hline 5 & Kebersihan dan kerapian & $1-4$ \\
\hline 6 & Finishing & $1-4$ \\
\hline \multicolumn{2}{|c|}{ Jumlah } & $6-24$ \\
\hline
\end{tabular}

\section{SIMPULAN DAN SARAN}

Dari pebahasan pada bab sebelumnya tentang analisis karya siswa kelas VII SMP Negeri 3 Sinjai Tengah dan teknik penilaian guru terhadap karya siswa, kriteria dalam menganalisis karya gambar siswa yaitu dari aspek proporsi, aspek komposisi, aspek terang gelap, perspektif, kebersihan/kerapihan, dan finishing. karya siswa berjumlah 25 karya yang mandapat kategori sangat baik yaitu berjumlah 1 karya (4\%), yang mendapat kategori baik yaitu berjumlah 2 karya $(8 \%)$, yang mendapat kategori sedang yaitu berjumlah 14 karya (56\%). Dan yang mendapat kategori kurang yaitu berjumlah 8 karya (32\%).

Teknik penilaian guru mata pelajaran seni budaya dalam menilai karya gambar bentuk siswa menggunakan tiga poin penilaian yaitu dari segi bentuk, kebersihan, dan kerapian karya. Guru mata pelajaran tidak menggunakan banyak aspek-aspek dalam menggambar bentuk ketika menilai karya siswa.

\section{DAFTAR PUSTAKA}

Apriyatno, Veri. 2003. "Cepat dan Mudah Belajar Menggambar dengan Pensil”. Jakarta Selatan: Kawan Kita.

Depdiknas. 2007. "Kamus Besar Bahasa

Indonesia”. Jakarta: Balai Bahasa. 
Depdiknas. 2014. "Seni Budaya SMA Kelas $X$ ”.Jakarta: Pusat Kurikulum dan Perbukuan.

Depdiknas. 2004. "Pedidikan Seni Rupa SMP Kelas 2".Jakarta: Pusat kurikulum dan Pembukuan.

Haling, Abd, dkk. 2007. "Perencanaan pengajaran". Makassar: Badan Penerbit Universitas Negeri Makassar.

Sachari, Agus. 2004. “ Seni Rupa Desain SMA Untuk Kelas X”. Jakarta: Erlangga.

Salam, Sofyan. 2001. " Pendidikan Seni Rupa Di Sekolah Dasar”. Makassar: Penerbit UNM.

Sulastianto, Harry. 2007. "Seni Budaya Utuk Kelas X”. Bandung: Grafindo Media Prata.

Sukardi. 2015. “Analisis Terhadap Materi Seni Rupa Dalam Mata Pelajaran Seni Budaya Pada Buku Siswa Kelas VII Semester 1 Berdasarkan Kurikulum 2013”. Skripsi: FSD UNM.

Suwarna. 2007. “ Menggambar Pendidikan Anak Usia Dini Fakultas Ilmu Pendidikan ". Yogyakarta: Universitas Negeri Yogyakarta.

Wahid, A. Kahar dan Pangeran Paita Yunus. 2014. "Apresiasi Seni”. Makassar: CV. Prince Publishing.

\section{Sumber dari Internet:}

https://www.klikoffice.co.id/meja-kerjapanel-ergostar

http://multisaranacetak.com/productspage/bahan-baku/gelas-208-ut08.html

https://www.google.com/search?q=jateng.trib unnews.com+buah+buahan\&safe=stri ct\&source $=\operatorname{lnms} \&$ tbm $=$ isch \&sa $=X \& v$ ed=0ahUKEwiy5bqp2dDhAhUmT48 KHbBvCt0Q AUIDigB\&biw $=1366 \&$ bih=657\#

https://www.google.com/search?q=kaskus.co.i $\underline{\mathrm{d}+\mathrm{krayon} \& \mathrm{safe}=\text { strict } \& \text { source }=\operatorname{lnms}}$ \&tbm $=$ isch \&sa $=X \& v e d=0$ ahUKEwia noLp4NDhAhUMuY8KHf9HA3MQ AUIDigB\&biw $=1366 \&$ bih=657\#

https://www.google.com/search?safe=strict \&b $i \mathrm{w}=1366 \& \mathrm{bih}=657 \& \mathrm{tbm}=\mathrm{isch} \& \mathrm{sa}=1$ \&ei=6cWzXLmDJaGEmgfXv4b4Bw $\underline{\text { q }=\text { melitassi.blogspot+spidol\&oq=m }}$ elitassi.blogspot+spidol\&gs_l=img.3.. .2695.5589..6083...0.0..0.156.879.0j7. …1.......gws-wiz-img.J7607qkXgLg\#

\section{SUMBER DARI WAWANCARA}

Guru Mata Pelajaran Seni Budaya SMP

NEGERI 3 Sinjai Tengah 